\title{
Assessment of plasma levels of IL-9 and IL-17 in patients with Immune thrombocytopenia
}

\author{
M.A.Zidan ${ }^{1}$, A.M.Abdelrahman ${ }^{1}$, R.A.Khashaba ${ }^{1}$, A.M.Diab ${ }^{2}$ and S.M.Shalaby ${ }^{1}$ \\ ${ }^{1}$ Clinical and Chemical pathology, Dept., Faculty of Medicine, Benha Univ., Benha, Egypt \\ ${ }^{2}$ Pediatric medicine, Dept., Faculty of Medicine, Benha Univ., Benha, Egypt \\ E-mail: Shalaby@yahoo.com
}

\begin{abstract}
Background: Immune thrombocytopenia (ITP) is an autoimmune disorder associated with decreased platelet production and accelerated platelet destruction lead to thrombocytopenia and mucocutaneos bleeding. It is usually a benign, self-limiting disease in children. An impaired immune system may be associated with ITP. objectives: The aim of this study was to assess the level IL-17 among active patients in relation to control. Subjects and methods : This study was a case-control study. The study included 20 patients with acute ITP. The patients were recruited from Pediatric hematology outpatient clinics and departments, Benha University Hospitals. In addition, 20 healthy children of comparable age and sex were taken as controls. Informed consents were obtained. Results: There was no statistically significant difference between cases and control regarding HB and WBCs but value of platelets was significantly lower among cases than control. . IL -17 level was Significantly higher in ITP cases when compared to control groups . Conclusion: This study concluded that, IL-17 may contribute to the pathogenesis of ITP. It could be potential biomarker that diagnose and predict the clinical course of ITP.
\end{abstract}

Key words: Immune thrombocytopenic purpura.

\section{Introduction}

Immune thrombocytopenia (ITP) is an autoimmune bleeding disorder in association with increased platelet destruction and impaired platelet production characterized by a diminished peripheral platelet count $(<100 \times 109 / \mathrm{L})$ with an increase of mucocutaneous bleeding [1].

It is usually a benign, self-limiting disease in children .The diagnosis of ITP depends on clinical characteristics and the laboratory examinations conducted with exclusion other diseases associated with thrombocytopenia [2].

ITP is an immune dysregulation-related disorder, characterized by loss of tolerance of the immune system to self-antigens expressed on the surface of platelets and megakaryocytes [3]. A large body of evidence demonstrated that ITP is primarily due toFc receptor $(\mathrm{FcR})$-mediated phagocytosis and destruction bymacrophages in the reticuloendothelial system in the spleen [4].

There are abnormalities of CD4+ T cell subsets in ITP patients. CD4+ T cells play an important role in the acquired immune system, including

promoting the differentiation and maturation of B cells, assisting the proliferation and differentiation of CD8+ T cells and other immune cells, as well as coordinating the interaction between different immune cells. Therefore, CD4+ T cells play a very important role in the pathogenesis of ITP [5].

Th17 is an important subset of CD4+Tcells that has been found to play important roles in the development of several autoimmune diseases, such as systemic erythematous lupus, rheumatoid arthritis and multiple sclerosis. As a classical autoimmune disorder, ITP has also been reported to have an aberrant Th17 cells. Th17 cells are significantly higher in active ITP patients than healthy controls. By releasing IL-17A and IL-17F in response to IL-33,
Th17 cell could promote the production of a variant of pro-inflammatory molecules such as IL-6, IL-8 and granulocyte colony-stimulation factor, thus aggravating the immunologic derangement characteristic of ITP [6].

\section{Subjects and methods}

This study was a case control study, it was conducted on 20 children patients (Patients' Group) in addition to 20 age-and sex-matched healthy subjects (Control Group).

The study was approved by the ethics committee of Benha University and written informed consent was obtained from the patients' legal guardians or the patients themselves before sampling

All participated children conducted from Benha University Hospitals.

\subsection{Inclusion criteria}

- Male or female children patients diagnosed as ITP

- ITP was confirmed by :Complete blood count, bone marrow aspiration.

\subsection{Exclusion criteria}

Patients were excluded from the study if they had:

- History of concomitant autoimmune disorders, such as systemic lupus erythematosis (SLE) or medications known to cause thrombocytopenia.

- Suspicion for malignancy, or presence of splenomegaly

- Manifestations of active infection.

\subsection{Methods}

All children in this study were subjected to the following: 
- Full history taking :including patient age, history of previous viral infection, bleeding episodes and purpuric eruption.

- Clinical examination: skin purpuric eruption, mucous membrane bleeding and presence or absence of splenomegaly.

- Laboratory investigations:

a. Complete blood count ( $\mathrm{CBC})$ :

b. Bone marrow examination (Patients only):

c. Serum interleukin 17 (IL-17) levels by ELISA technique.

\section{Results}

There was no statistically significant differences among studied and control groups regarding hemoglobin level and total leucocyte count, while platelets was significantly lower in patients group compared to control group Table (1)

There were one patient $(5.0 \%)$ were asymptomatic at diagnosis, five patients $(25.0 \%)$ were presented with preceding febrile illness, nineteen patients $(95.0 \%)$ had skin manifestation, four patients $(20 \%)$ had bleeding tendency and non of patients had organomegaly (Table (2).

IL-17 was significantly higher in patients group compared to control group Table (3).

Table (1) Comparison between hematological data of Patients'group at diagnosis and that of control group.

\begin{tabular}{llccc}
\hline & & $\begin{array}{c}\text { Group I } \\
(\mathbf{n}=\mathbf{2 0})\end{array}$ & $\begin{array}{c}\text { Group II } \\
(\mathbf{n}=\mathbf{2 0})\end{array}$ & P value \\
\hline HB $(\mathbf{g} / \mathbf{d l})$ & Mean \pm SD & $11.5 \pm 0.7$ & $11.9 \pm 0.5$ & 0.263 \\
WBCs $\left(* 1 \mathbf{1 0}^{\mathbf{9}} / \mathbf{L}\right)$ & Mean \pm SD & $7 \pm 1.3$ & $7.4 \pm 1.7$ & 0.470 \\
Platelets $(* \mathbf{1 0} / \mathbf{L})$ & Mean \pm SD & $18 \pm 17$ & $263 \pm 40$ & $<0.001$ \\
\hline
\end{tabular}

Independent $t$ test was used

Table (2) Clinical characteristics of the patients group.

\begin{tabular}{lll}
\hline & N & \% \\
\hline Asymptomatic & 1 & 5.0 \\
Preceding febrile illness & 5 & 25.0 \\
Skin manifestation & 19 & 95.0 \\
Active bleeding & 4 & 20.0 \\
Organomegaly & 0 & 0.0 \\
\hline
\end{tabular}

Table (3) comparsion between patients and control as regard IL17 levels.

\begin{tabular}{|c|c|c|c|c|}
\hline & & $\begin{array}{l}\text { Group I } \\
(\mathbf{n}=\mathbf{2 0})\end{array}$ & $\begin{array}{c}\text { Group II } \\
(\mathbf{n}=\mathbf{2 0})\end{array}$ & $P$ value \\
\hline IL17(pg/ml) & Mean \pm SD & $5.24 \pm 1.04$ & $2.27 \pm 0.82$ & $<0.001$ \\
\hline
\end{tabular}

Independent $t$ test was used

\section{Discussion}

This case-control study was conducted on twenty patients attended the pediatric hematology outpatient clinics and departments, Benha University Hospitals diagnosed with ITP during the active state after exclusion of those with history of concomitant autoimmune disorders, such as systemic lupus erythematosis (SLE) or medications known to cause thrombocytopenia, those with suspicion for malignancy, or presence of splenomegaly and presence of manifestations of active infection, in addition to twenty age-and sex-matched healthy controls.

All patients included in this study were subjected to full history taking including patient age, history of previous viral infection, bleeding episodes and purpuric eruption, clinical examination for presence of bleeding and spleenomegaly, laboratory investigations involving $\mathrm{CBC}$, Bone marrow examination ,serum interleukin 17(IL-17) level analysis by ELLISA technique.

In the current study, showed no statistically significant difference in the $\mathrm{Hb}$ concentration was detected in ITP patients in comparison to controls.

This was in agreement with another studies performed by Hassan et al., [7] and Khalifa et al.,[8] showed no significant difference in the $\mathrm{Hb}$ concentration was detected between the studied group.

On the contrary, in a study performed by soliman et al., [9] who reported decrease in the $\mathrm{Hb}$ concentration in ITP patients in comparison to controls.

According to TLCs, the present study was in agreement with those of Khalifa et al. [8] and Zahran 
et al., [2], who also reported no statistically significant difference between ITP patients and controls. However, Fahim and Monir [10] found that the TLC count was significantly higher in ITP patients than in controls; this may have been because of neutrophilia or lymphocytosis that may accompany the disease..

As regards to clinical presentation in patient group, one patient $(5.0 \%$ was asymptomatic at diagnosis, five patients $(25.0 \%)$ presented with preceding febrile illness, nineteen $(95.0 \%)$, had skin manifestation, four patients $(20 \%)$ had bleeding tendency and non of patients had organomegaly,

In Khalifa et al., [8] study showed Purpura, ecchymosis and mucous membrane bleeding (90.9\%, $81.81 \%$ and $72.7 \%$ respectively) were the most common clinical data among ITP cases group. Less common splenomegaly and lymphadenopathy were $(4.54 \%$ and $.0 \%)$ respectively.

In another study performed by Talaat et al.,[11] the cutaneous manifestations were present in all patients $(100 \%)$ in the form of petechial rash and epistaxis.

In the current study, there was a statistically significant elevation in serum level of IL-17 in patients group compared to control group. Our results were in agreement with Zhou et al., [12] study that found that the serum concentration of IL-17 in ITP patients was higher than in healthy subjects

Also, Okamoto et al., [13] study that included 33 ITP patients compared to 11 healthy control group, found increased expression of IL-17 in patients with ITP than in the control subjects.

IL-17 has potent immunogenic properties. It induces the release of colony stimulating factors, chemokines, metalloproteinases, tumor necrosis factor alpha, and IL-6 which enhances the production of antiplatelet antibodies in mice and in patients with ITP. Moreover, IL- 17 mobilizes and activates neutrophils. IL- 17 alone or in combination with Bcell activating factor (BAFF) protects $\mathrm{B}$ cells from apoptosis, promotes B-cell proliferation and drives plasma cell differentiation, probably playing a role in in the pathogenesis of ITP [14].

\section{Conclusion}

In conclusion, this study showed that IL-17 was elevated in patient group especially those with sever thrombocytopenia versus control group. Therefore it could be potential biomarker that diagnose and predict the clinical course of ITP.

\section{Funding}

There was no funding for this work.

\section{Declaration of competing interest}

The authors declare that there are no conflicts of interest.

\section{References}

[1] A.A.Erikçi, B. Karagöz, and O.Bilgi. Regulatory $\mathrm{T}$ cells in patients with idiopathic thrombocytopenic purpura. Turkish Journal of Hematology.vol. 33(2),pp. 153,2016.

[2] AM.Zahran, SS.Aly, A.Elabd. Regulatory and memory B lymphocytes in children with newly dignosed immune thrombocytopenia. J Hematol.vol. 6(4),pp.81,2017.

[3] J.Johnsen.Pathogenesis in immune thrombocytopenia new insights. Hematology Am SocHematolEduc Program.vol. 41,pp.306,2012.

[4] I.Raphael, S.Nalawade, TN.Eagar. T cell subsets and their signature cytokines in autoimmune and inflammatory diseases. Cytokine.vol.74,pp.5,2015.

[5] D.Wu , Y.Liu , N.Pang . PD-1/PD-L1 pathway activation restores the imbalance of Th1/Th2 and treg/Th17 cells subtypes in immune thrombocytopenic purpura patients. Medicine.vol.98,pp.43,2019.

[6] ShuangL, X.You-Zhen L.Toa. Interleukin17A and $-17 \mathrm{~F}$ Gene Polymorphisms in Chinese Population with Chronic Immune Thrombocytopenia .Annals of clinical \& Laboratory Science.vol.46(3),pp.291,2016.

[7] T.H.Hassan, A.S.Ahmed and N.R.AbdelFattah. Interleukin 27 Serum Level And Its Prognostic Significance In Children With Immune Thrombocytopenia. Zagazig University Medical Journal.vol.26(1),pp.132,2020.

[8] N.A.Khalifa, M.A.Hesham, M.Shaaban. Study of interlukin-33 in idiopathic thrompocytopenicpurpura in children. Zagazig University Medical Journal.vol.25(1),pp.164,2019.

[9] MA.Soliman, SM.Kamal, El-Hawy and ElShafey. Role of cellular immunity in the pathogenesis of immune thrombocytopenicpurpura in children. Menoufia Medical Journal.vol. 31,pp.550,2018.

[10] NM.Fahim and E.Monir. Functional role of CD4+CD25+ regulatory $\mathrm{T}$ cells and transforming growth factor-betal in childhood immune thrombocytopenic purpura. Egypt J Immunol.vol.13,pp.173,2006.

[11] R.M.Talaat, A.M.Elmaghraby, S.S.Barakat. Alterations in immune cell subsets and their cytokine secretion profile in childhood idiopathic thrombocytopenic purpura (ITP), Clin. Exp. Immunol.vol.176 (2),pp. 291,2014.

[12]Z.J.Zhou, Y.S.Zhang , C.X.Liang . Role of Th9, Th17, Treg Cells levels and IL-9, IL-17 and TGF- $\beta$ Expression in Peripheral Blood of Patients with ITP in Pathogenesis of ITP Chinese Journal of Microbiology and Immunology.vol.27(1),p.180,2019. 
[13] N.Okamoto ， M.Homma , Y.Kawaguchi. Increased expression of interleukin-17 is associated with macrophages in chronic immune thrombocytopenia. International journal of clinical and experimental pathology.vol.11(5),pp.2419, 2018.

[14] O.Ghallab , N.A.Hamed, M.Gamal . Evaluation of Interleukin-17 and Gamma Interferon Levels in Primary Immune and Borderline Thrombocytopenia. Journal of the Egyptian Society of Haematology \& Research .vol.10,pp.1,2014. 